\title{
Enteral nutrition as primary therapy in short bowel syndrome
}

\author{
I W Booth
}

\begin{abstract}
The spectacular success of parenteral nutrition in supporting patients during small intestinal adaptation after massive resection, tends to obscure the prolonged periods often needed for such adaptation to take place. After neonatal small intestinal resection for example, it may take more than five years before adaptation is complete. There is therefore a strong argument for examining ways in which adaptation can be facilitated, in particular, by the addition of novel substrates to enteral feeds. Pectin is completely fermented by colonic bacteria to short chain fatty acids. In the rat, addition of pectin to enteral feeds led to a more rapid adaptive response in both the small and large intestine after massive small intestinal resection, although faecal nitrogen losses were increased. In a similar rat model, the provision of $40 \%$ of nonprotein energy as short chain triglycerides facilitated the adaptive response in the jejunum, colon, and pancreas. The importance of glutamine as a metabolic substrate for the small intestine makes it another potential candidate and some, but not all animal studies, have suggested a therapeutic effect: increasing the glutamine content of feeds to $25 \%$ of total amino acids produced enhanced jejunal and ileal hyperplasia, even on a hypocaloric feed, and an improved overall weight gain. Studies in humans are very limited, but such promising results in the experimental animal suggest that this is probably a fruitful area for further study. (Gut 1994; supplement 1: S69-S72)
\end{abstract}

Resection of more than $50 \%$ of the small intestine is probably associated with important nutritional sequelae, and when $25 \%$ or less remains, nutritional support, often by the parenteral route initially, is essential. This review summarises recent experience in optimising the constituents of enteral feeds to enhance postresection intestinal adaption.

Institute of Child Health University of Birmingham I W Booth

Correspondence to: Professor I W Booth, Institute of Child Health, Francis Road, Birmingham B16 8ET. study reported an increase in the survival of children with less than $40 \mathrm{~cm}$ of small intestine from $42 \%$ before 1980 to $94 \%$ in the decade since. ${ }^{1}$ When $40-80 \mathrm{~cm}$ of small intestine remain, current longterm survival is $97 \% .^{1}$ This success story, however, obscures the time needed for full intestinal adaptation to take place, and some children have to receive parenteral nutrition for six years before eventually stopping treatment. Even the mean time to adaptation when less than $40 \mathrm{~cm}$ of small intestine remains varies from 18 to 45 months, depending on whether the ileocaecal valve is present. ${ }^{1}$

It is therefore appropriate to examine those factors that regulate adaptation so they can be manipulated to accelerate this process.

\section{Control of postresection adaptation ${ }^{2}$}

After small bowel resection, the remaining intestine dilates, and crypt depth and villus height increase, leading to enhanced segmental absorption of many nutrients. In the rat, mucosal DNA synthesis increases within 24 hours, leading to villus hyperplasia, which is fully established by one month. In humans, however, the adaptive response seems to be slower and often takes over a year to reach maximal effect. The finding that total parenteral nutrition leads to a more muted mucosal hypoplasia in humans than in the experimental animal is consistent with a comparatively less important role for luminal nutrients in maintaining normal intestinal function in humans ${ }^{3}$ and a longer period for adaptation.

Three main factors are responsible for promoting intestinal adaptation: pancreatobiliary secretions, hormonal factors, and luminal nutrients. Clearly, only the last is of direct relevance to the role of enteral nutrition as primary therapy in SBS.

\section{LUMINAL NUTRIENTS}

A number of strands of evidence support the role of luminal nutrients in promoting adaptation. Jejunal resection by bypass, or ileojejunal transposition, all lead to hyperplastic changes in the segment exposed to increased nutrients. Similarly, mucosal growth may be stimulated by cold induced hyperphagia in the rat, or by luminal perfusion of nutrients into Thiry-Vella fistulas in the dog.

It has been recognised for some time that the adaptive response can be influenced by dietary components. For example, disaccharides seem to be more trophic than monosaccharides, provided the disaccharides are hydrolysed ${ }^{4}$; a high protein diet leads to over the last 15 years, mainly because longterm parenteral nutrition permits affected children to grow and develop normally during the period of intestinal adaptation. One recent

\section{Prognosis}




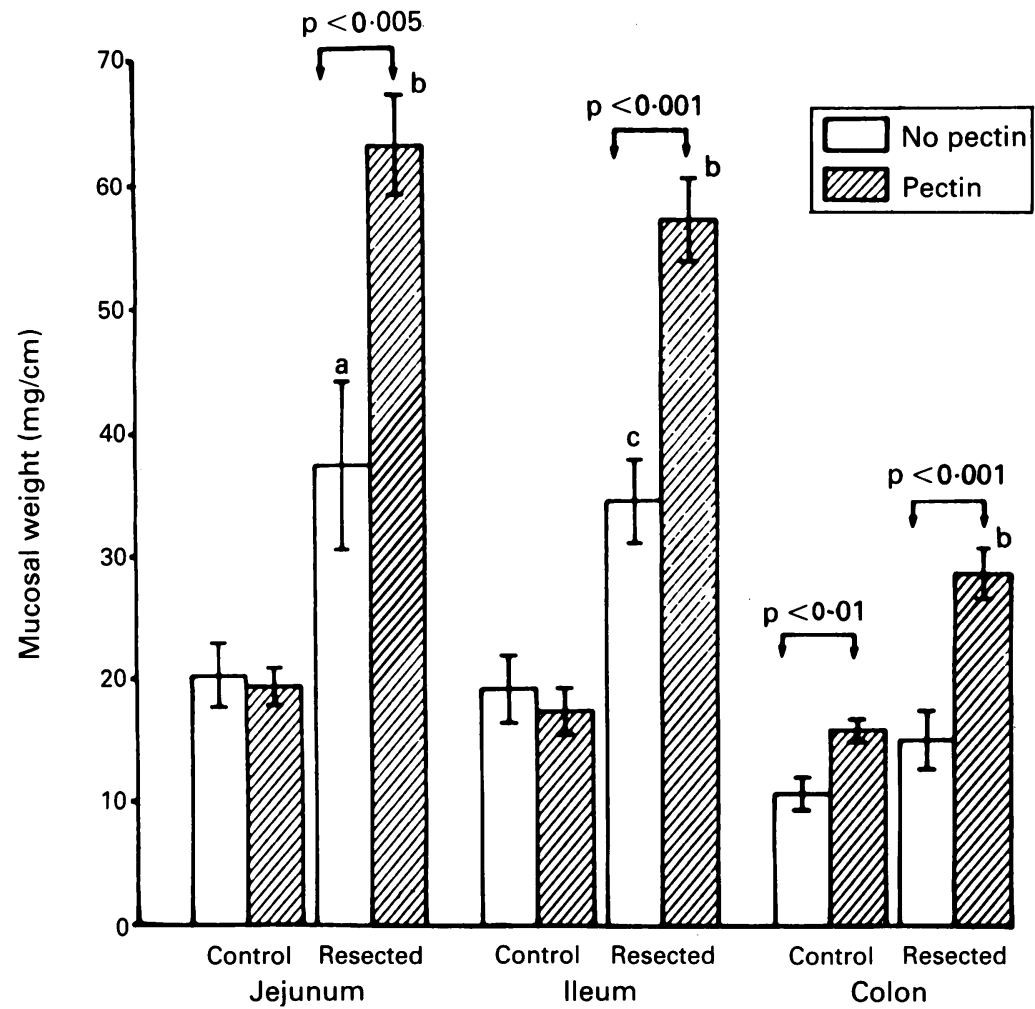

Figure 1: The effects on mucosal weights $(\mathrm{mg} / \mathrm{cm})$ of pectin supplementation of feeds after $80 \%$ small bowel resection in the rat $(a: p<0.04 \mathrm{v}$ no pectin control; $b: p<0.001 \mathrm{v}$ pectin control in each segment; $c: p<0.003 \mathrm{v}$ no pectin control) ${ }^{12}$

increased peptide hydrolase and alkalinephosphatase activities, and dietary starch leads to increased disaccharidase activities. ${ }^{5}$ Long chain triglyceride seems to be a more potent trophic stimulus than protein, starch or median chain triglyceride. ${ }^{6}$

More recently, the role of a number of dietary components not normally included in postresection enteral feeds has been examined: dietary fibre, free fatty acids, and short chain triglycerides and glutamine. To date, they have been studied almost exclusively in the rat, although preliminary data suggest a potential role in reducing the duration of postresection adaptation in humans. In addition, changing composition of carbohydrates in enteral feeds may also be helpful in preventing recurrent D-lactic acidosis complicating massive small bowel resection.

\section{Specific nutrients as primary therapy}

\section{ENHANCED ADAPTATION}

\section{Pectin}

Pectin is a water soluble, non-cellulosic dietary fibre, which is completely fermented by colonic bacteria, leading to an increase in stool fatty acid concentrations without an increase in bulk. ${ }^{7}$ Interest in pectin in the context of intestinal adaptation followed the finding that pectin supplementation of an elemental diet was associated with improved healing of colonic anastomoses in the rat: pectin treated animals had higher bursting pressure and a higher hydroxyproline content at the anastomotic site. ${ }^{8}$

Importantly, changes have also been found in the small intestine. Addition of pectin to the diet in the rat resulted in an increase in small intestinal length and weight and an increase in crypt depth in the mid jejunal and ileal segments. ${ }^{9}$ The migration rate of enterocytes up the villus was also increased by pectin feeding, leading to a reduction in cell transit time. ${ }^{10}$

Studies in the experimental animal - Koruda et al have investigated the effects of a pectin supplemented elemental diet on intestinal adaptation to massive small bowel resection in the rat. ${ }^{11} 12$ After an $80 \%$ small bowel resection and anastomosis, animals were allocated to receive gastrostomy feeds of an elemental diet, with or $\overrightarrow{0}$ without the addition of citrus pectin $(2 \mathrm{~g} / 100$ $\mathrm{ml})$. Animals were killed 15 days postoperatively, after eight days on the full diet. Control animals were gastrostomy fed but not resected. As expected, resection led to increases in bowel weight/unit length, but this hypertrophy was significantly increased in the ileal and colonic segment by pectin supplementation. In the resected animals, pectin significantly increased mucosal weight (Fig 1) and DNA, RNA, and protein content by $1 \cdot 3-2 \cdot 0$-fold in jejunal, ileal, and colonic segments. Pectin feeding also increased villus height, crypt depth, and mucosal thickness in both jejunum and ileum, although with the exception of mucosal depth, these improvements were only significant in the ileum (Table I). Mitotic activity/crypt was significantly greater in the jejunum and colon of the pectin group than the non-pectin animals. Interestingly, weight loss in the resected animals was significantly reduced by pectin supplementation, even though nitrogen balance was reduced by pectin as a result of increased faecal nitrogen losses. After resection, and in the absence of pectin supplementation, ileal segmental sucrase, maltase, and lactase activities were increased in the ileum but only maltase activity in the jejunum. Pectin supplementation, however, led to significant increases in the segmental activity of all three disaccharidases in the jejunum (Table II).

Experience in humans - There has been only one case report so far of the effects of pectin supplementation of enteral feeds, in a 3 year old boy with only $18 \mathrm{~cm}$ of jejunum after a small bowel volvulus. ${ }^{13}$ In contrast with studies in the experimental animal, pectin did not have

TABLE I Pectin and postresection adaptation in the rat ${ }^{12}$

\begin{tabular}{|c|c|c|c|}
\hline & fejunum & Ileum & Colon \\
\hline Weight/length & - & + & + \\
\hline Mucosal weight & + & + & + \\
\hline DNA & + & + & + \\
\hline RNA & + & + & + \\
\hline protein & + & + & + \\
\hline Villus height & - & + & + \\
\hline Crypt depth & - & + & N/A \\
\hline Mucosal thickness & + & + & N/A \\
\hline
\end{tabular}

TABLE II Pectin and postresection adaptation in the rat ${ }^{12}$

$\begin{array}{llc}\text { Segmental acitivity } & \text { fejunum } & \text { Ileum } \\ \text { Sucrase } & \uparrow & \downarrow \\ \text { Maltase } & \uparrow & - \\ \text { Lactase } & \uparrow \uparrow & -\end{array}$




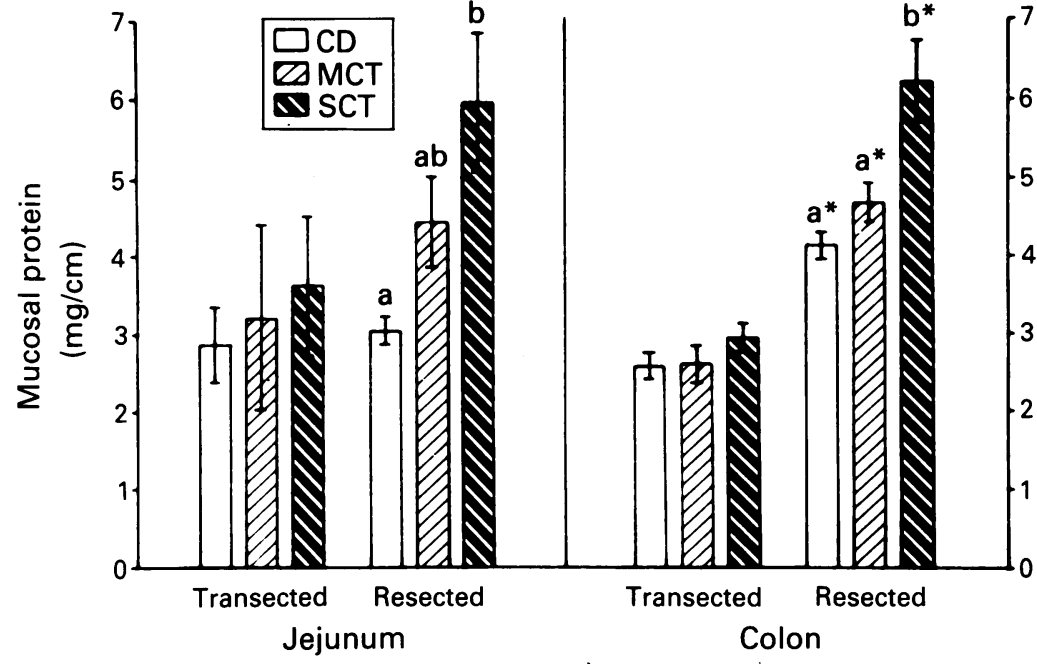

Figure 2: The effects on mucosal protein $(\mathrm{mg} / \mathrm{cm})$ for each intestinal segment of resected and transected (control) rats fed chemically defined (CD), medium chain triglyceride (MCT) or short chain triglyceride (SCT) diets. Resected groups with different letters differ significantly (in the jejunum, $p<0.05$; in the colon $p<0 \cdot 01$ ). ${ }^{\star}$ Significantly different from the respective transected control $p<0 \cdot 01)^{21}$ an adverse effect upon nitrogen balance, in fact, nitrogen absorption improved somewhat. Pectin supplementation was associated with prolongation of stomach to anus transit time, and there were no adverse effects on electrolyte balance. Mineral balances, a potentially adverse effect of pectin, were not studied.

Mechanisms - There are a number of possible mechanisms whereby pectin might influence intestinal adaptation after resection. An effect in the colon is not surprising; pectin fermentation produces short chain fatty acids, the preferred oxidative substrate for colonocytes, metabolism of which leads to colonic mucosal proliferation. ${ }^{14} 15$ An effect in the small intestine may be related to an increase in transit time and consequently more contact with luminal nutrients, ${ }^{16}$ stimulation of pancreatic secretion, ${ }^{17}$ or enteroglucagon release, ${ }^{16}$ glutamine and ketone production, or increased gut blood flow. ${ }^{18}$

\section{Soy polysaccharide}

In a short term six hour study in six patients with SBS, the addition of soy polysaccharide to an enteral feed delayed transit but was associated with increased stool wet weight and sodium output, together with decreased energy absorption. ${ }^{19}$

\section{Short chain triglycerides}

Short chain triglycerides are handled in the small intestine like medium chain triglycerides. They are hydrolysed by pancreatic and gastric lipase and are well absorbed in both the hydrolysed and esterified form. In contrast with medium chain triglycerides, the component short chain fatty acids of short chain triglycerides are absorbed by the colonic epithelium as well as in the small intestine and stimulate intestinal mucosal growth in the rat. ${ }^{20}$

Recently Kripke et $a^{21}$ have investigated the effect of short chain triglycerides on intestinal adaptation during $60 \%$ small bowel and caecal resection in the rat. Animals were allocated to receive a low fat, chemically defined feed, or a feed in which part of the carbohydrate was replaced with either medium or short chain triglycerides ( $40 \%$ of non-protein energy). After 12 days the group receiving the short chain triglyceride had significantly greater segment and mucosal weight and protein content in the jejunum and colon, than the group receiving the medium chain triglyceride or low fat diets (Fig 2). Resection increased the comparative weight of the pancreas compared with controls, and this was again increased maximally in the group receiving the short chain triglyceride diet.

\section{Free fatty acids}

Free fatty acids seem to be even more potent than long chain triglyceride, protein, starch or medium chain triglyceride in enhancing adaptation. ${ }^{622}$ After $50 \%$ small bowel resection in the rat, infusion of $10 \%$ of the total calories as fatty acids (50:50 wt/vol mixture of oleic and linoleic acid) resulted in enhanced small intestinal and colonic adaptation compared with an equivalent amount of long chain triglyceride. ${ }^{12}$

\section{Glutamine}

Glutamine is a non-essential amino acid and is the most abundant amino acid in plasma, where it accounts for $20 \%$ of the total circulating pool. Nearly all tissues are capable of glutamine synthesis, but most is synthesised and stored in muscle, where its concentration is 30 times that of plasma. Glutamine is an important vehicle for nitrogen transport between tissues, a regulator of protein synthesis, the most important substrate for renal ammoniagenesis, and is an essential precursor for nucleotide synthesis. It is also an important metabolic fuel for rapidly dividing cells, including the small intestinal mucosa, and after small bowel resection, glutamine released from muscle stores is taken up by the gut. ${ }^{23}$

Supplementing parenteral nutrition fluids with glutamine reduces the gastrointestinal atrophy seen during parenteral nutrition ${ }^{2425}$ and the severity of the mucosal injury after chemotherapy or radiation treatment. ${ }^{26}$

Glutamine provided enterally may enhance postresection adaptation. Increasing the glutamine content of enteral feeds so that it provided $25 \%$ of total amino acids instead of the usual $4-10 \%$, resulted in enhanced hyperplasia in the jejunum and ileum. ${ }^{27}$ In pair fed animals, glutamine supplementation led to enhanced body weight, which was again maximal when glutamine provided $25 \%$ of total amino acid. Glutamine may also be capable of inducing postresection hyperplasia where the animals receive only $50 \%$ of their energy requirements enterally. ${ }^{27}$ These findings have not been confirmed by others. ${ }^{28}$ It seems then, that glutamine may have an anabolic effect on body tissues in addition to its effects on intestinal adaptation, although it is noteworthy that the requirement for dietary glutamine under these circumstances far exceeds the glutamine content of a normal diet. 
PREVENTION OF D-LACTIC ACIDOSIS

Recurrent D-lactic acidosis is an uncommon complication of SBS. Carbohydrate that escapes small intestinal absorption enters the colon and is fermented to the D-L-isomers of lactates when lactobacilli are present in the colon. Although L-lactate can be metabolised by L-lactate dehyrogenase, no such pathway exists for D-lactate, and patients have severe acidosis and a considerable disturbance in the level of consciousness. ${ }^{29}$ Treatment is usually directed at changing the colonic flora by giving broad spectrum antibiotics orally. ${ }^{30} \mathrm{We}$ recently described a child in whom it was possible to prevent recurrent symptoms by modifying the patient's enteral feed. ${ }^{31}$

At the age of 9 the patient had a massive resection after a small bowel volvulus, which left her with $14 \mathrm{~cm}$ of jejunum. Superior venacaval obstruction prevented longterm parenteral nutrition, and the patient was dependent upon enteral feeds. Recurrent D-lactic acidosis occurred initially after sucrose binges, but continued despite strict adherence to a low sucrose diet in addition to enteral nutrition. Stool culture showed a pure growth of lactobacilli. Because this patient's colon represented a potentially valuable source of nutrient salvage, it was decided not to use broad spectrum antibiotics, but to attempt to reduce D-lactic acid production by modifying the nature of the carbohydrate substrate entering the colon. Test of fermentation by lactobacilli in vitro showed $\mathrm{D}$-lactate production from a wide range of mono and disaccharides, but none from starch. The patient was therefore switched from a feed in which the carbohydrate was mainly oligosaccharide, to a feed in which over $75 \%$ of the carbohydrate was present as pentasaccharides or larger. The patient had no further episodes of acidosis and thrived. ${ }^{31}$

It is now clear that dietary modification is capable of enhancing postresection adaptive hyperplasia in the experimental animal. In addition to conventional nutrients, supplementation of enteral feeds with pectin, short chain triglycerides, free fatty acids, and glutamine may be important in this respect, but there has been very little experience of similar dietary modification in humans. The difficulties of proving a beneficial effect in humans should not be underestimated. Patients with severe SBS, the group in whom enhanced adaptation will probably be of most benefit, are not common, and the nature of the disorder and of the intervention do not lend themselves readily to a cross over design. There is now sufficient evidence, however, in the experimental animal to support further studies in humans.

Finally, it should be remembered that modification of the composition of enteral feed composition may have a role in the primary treatment of recurrent D-lactic acidosis secondary to SBS.

1 Goulet OJ, Revillon Y, Jan D, et al. Neonatal short bowel syndrome. F Pediatr 1991; 119: 18-23.

2 Dowling RH. Small bowel adaptation and its regulation. Scand $f$ Gastroenterol 1982; 17 (suppl): 53-74.

3 Guedon C, Schmitz J, Lerebours E, Metayer J, Audran E, Hemet J, Colin R. Decreased brush border hydrolase activities without gross morphologic changes in human intestinal mucosa after prolonged total parenteral nutrition of adults. Gastroenterology $1986 ; 90: 373-8$.

4 Weser E, Babitt J, Hoban M, Vandeventer A. Intestinal adaptation. Different growth responses to disaccharides compared with monosaccharides in rat small bowel. Gastroenterology 1986; 91: 1521-7.

5 McCarthy DM, Nicholson JA, Kim YS. Intestinal enzyme adaptation to normal diets of different composition. $A m \mathcal{F}$ Physiol 1980; 239: G445-51.

6 Morin CL Grey BL Garofalo C. Influence of lipids on intestinal adaptation after resection. In: Robinson JWL, Dowling RH, Reicken EO, eds. Mechanisms in intestinal adaptations. Lancaster, England: MTP Press, 1981.

7 Spiller GA, Chernoff MC, Hill RA, Gates JA, Nassar JJ, Shipley EA. Effect of purified cellulose, pectic, and a lowresidue diet on fecal volatile fatty acids, transit time, and fecal weight in humans. Am f Clin Nutr 1980; 33: 754-9.

8 Rolandelli RH, Koruda MJ, Settle G, Rombeau JL. Effect on enteral feeding supplemented with pectin on the healing of colonic anastomoses in the rat. Surgery 1986; 99: 703-7.

9 Brown RC, Kelleher J, Losowsky MS. The effect of peptin on the structure and function of the rat small intestine. $B r$ f Nutr 1979; 42: 357-65.

10 Jacob LR Effects of dietary fiber on mucosal growth and cell proliferation in the small intestine of the rat: comparcell proliferation in the small intestine of the rat: compar-
ison of oat bran, pectin and guar with total fiber deprivaison of oat bran, pectin and guar
tion. Am $\mathcal{F}$ Nutr 1983; 37: 954-60.

11 Koruda MJ, Rolandelli RH, Settle RG, Saul SH, Rombeau $\mathrm{J} L$. The effect of a pectin-supplemented elemental diet on intestinal adaption to massive small intestinal resection. FPEN 1986; 10: 343-50.

12 Koruda MJ, Rolandelli RH, Settle RG, Rombeau JL. Small bowel disaccharidase activity in the rat as affected by intestinal resection and pectin feeding. Am $\mathcal{f}$ Clin Nutr 1988; 47: 448-53.

13 Finkel Y, Brown G, Smith HL, Buchanan E, Booth IW. The effects of a pectin-supplemented elemental diet in a boy with short gut syndrome. Acta Paediatr Scand 1990; 79: 893-986.

14 Roediger WEW. The starved colon - diminished mucosa nutrition, diminished absorption, and colitis. Dis Colon nutrition, diminished abso
Rectum. 1990; 33: 858-62.

15 Sakata T. Stimulatory effect of short-chain fatty acids on epithelial cell proliferation in the rat intestine: a possible explanation for trophic effects of fermental fibre, gut microbes and luminal trophic factors. Br $\mathcal{F}$ Nutr 1987; 58: 95-103.

16 Miazzi BM, Al-Mukhtar MYT, Salmeron M, et al. Hyperenteroglucagonaemia and small intestinal growth after colonic perfusion of glucose in rats. Gut 1985; 26 518-24.

17 Isaksson G, Asp NG, Ihse I. Effects of dietary fibre on pancreatic enzyme activities of ileostomy evacuates and on creatic enzyme activities of ileostomy evacuates and on Gastroenterol 1983; 18: 417-23.

18 Kvietys PR, Granger PR. Effects of volatile fatty acids on blood flow and oxygen uptake by the dog colon. $A m$ F Physiol 1981; 80: 962-9.

19 Rodrigues CA, Lennard-Jones JE, Thompson DG, Farthing MJG. The effects of octreotide, soy polysaccharide, coedeine and loperamide on nutrient, fluid and electrolyte absorption in the short gut syndrome. Aliment Pharmacol Therap 1989; 3: 159-69.

20 Kripke SA, Fox AD, Berman JM, Settle RJ, Rombeau JL. Stimulation of intestinal mucosal growth with intracolonic infusion of short-chain fatty acids. FPEN 1989; 13: 109-16.

21 Kripke SA, De Paula JA, Berman JM, Fox AD, Rombeau JL, Settle RG. Experimental short-bowel syndrome: effect of an elemental diet supplemented with short-chain triglyceride. Am f Clin Nutr 1991; 53: 954-62.

22 Grey VL, Garofalo C, Greenberg GR, Morin CL. The adaptation of the small intestine after resection in response to free fatty acids. Am $\mathcal{F}$ Clin Nutr 1984; 40: 1235-42.

23 Astre C, Gouttebel MC, Saint-Aubert B, Girardot PM, Briand D, Joyeux H. Plasma and jejunal gluten levels after extensive small bowel resection in dogs. Clin Nutr 1992, 11: $30-4$.

24 O'Dwyer ST, Smith RJ, Hwang TL, et al. Maintenance of small bowel mucosa with glutamine enriched parenteral small bowel mucosa with glutamine

25 Helton S, Jacobs DO, Bonner-Weir S, Bueno R, Smith RJ Wilmore DW. Effects of glutamine-enriched parentera nutrition on the exocrine pancreas. FPEN 1990; 14: nutrition

26 Klimberg BS, Souba WW, Dowlson DJ, et al. Prophylactic glutamine protects the intestinal mucosa from radiation injury. Cancer 1990; 66: 61-8.

27 Smith RJ, Wilmore DW. Glutamine nutrition requirements. FPEN 1990; 14: 94-9S

28 Vanderhoof JA, Park JHY, Mohammadpour H, Blackwood DA. Absence of tropic effect of glutamine on intestinal adaptation following massive small bowel resection. FPEN 1990; 14: 85

29 Perlmutter DH, Boyle JT, Campos JM, Egler JM, Watkins JB. D-lactic acidosis in children: an unusual metabolic composition of small bowel resection. $\mathcal{f}$ Pediatr 1983; 102: 234-8.

30 Anonymous. The colon, the rumen, and D-lactic acidosis [Editorial]. Lancet 1990; 336: 599-600.

31 Mayne AJ, Handy DJ, Preece MA, George RH, Booth IW. Dietary management of D Aactic acidosis in short bowel syndrome. Arch Dis Child 1990; 65: 229-31. 